\title{
CREEP OF CRACKED POLYMER FIBER REINFORCED CONCRETE UNDER SUSTAINED TENSILE LOADING
}

\author{
RUTGER VRIJDAGHS*, MARCO DI PRISCO ${ }^{\dagger}$ AND LUCIE VANDEWALLE ${ }^{\ddagger}$ \\ *Katholieke Universiteit Leuven (KU Leuven) \\ Heverlee, Belgium \\ e-mail: rutger.vrijdaghs@ bwk.kuleuven.be \\ ${ }^{\dagger}$ Politecnico di Milano \\ Milan, Italy \\ e-mail: marco.diprisco@polimi.it \\ ${ }^{\ddagger}$ Katholieke Universiteit Leuven (KU Leuven) \\ Heverlee, Belgium \\ e-mail: lucie.vandewalle@bwk.kuleuven.be
}

Key words: Creep, Fiber Reinforced Concrete, Tensile Creep, Crack Growth, Polymeric Fibers

\begin{abstract}
In fiber reinforced concrete (FRC), fibers are added to the fresh concrete mix in order to improve the residual tensile strength, the toughness and/or durability of a concrete element. Currently, structural applications remain relatively scarce as the time-dependent behavior of FRC is still poorly understood. This paper reports the first results of an experimental campaign regarding the creep of cracked polymer FRC. In the test setup, cylindrical, notched FRC specimens are considered. The concrete is reinforced with structural polymeric fibers for use in load-bearing applications. In a first step, the material is characterized according to the European Standard EN14651. Secondly, the samples are precracked to localize the creep deformations and to monitor the crack growth in time. The samples are subjected to a sustained tensile load, whereby different load levels with respect to the individual residual strength are considered. The results of the first months of creep loading will be detailed and discussed in the paper.
\end{abstract}

\section{INTRODUCTION}

Fiber reinforced concrete (FRC) is a composite material in which fibers are added to the fresh concrete mix [1,2]. These fibers are used to improve the properties of the concrete in the fresh or hardened state. In structural applications, fibers can partially or totally replace the traditional reinforcement. For these purposes, the fibers provide an enhanced post-cracking tensile strength in the hardened state by bridging crack faces [3]. Commercially available fibers can be made from a number of different materials: steel, glass, synthetic and natural fibers being the most common types [4]. Until recently, the research effort has been focusing on the properties of FRC in the fresh and hardened state [5, 6]. It has been found that the inclusion of fibers decreases plastic shrinkage cracking [7] and flowability [8] in the fresh state. In the hardened state, fibers provide a post-cracking strength as is shown in references [9-11]. However, investigations on the longterm structural properties of FRC only recently became a research focal point. The recently published Model Code 2010 [12] acknowledges that time-dependent effects may significantly 
alter the behavior of structural elements, both in the serviceability limit state and in the ultimate limit state. In the former, creep may cause unwanted and unacceptable deflections of FRC beams [13, 14], whilst in the latter, the residual load-bearing capacity of elements may be significantly lower than the design value based on short-term strength assessment. However, the Model Code does not provide design rules to take long-term behavior of FRC into account. It is clear that further research on the long-term structural properties of FRC is required. One of these time-dependent phenomena is creep. In this paper, an experimental setup for a uniaxial tensile creep test on polymeric FRC is presented. Furthermore, the results of the first month of creep are shown and discussed as well.

\section{EXPERIMENTAL SETUP}

\subsection{Overview}

The creep behavior of polymeric FRC is studied by applying a sustained tensile load to precracked, notched cylinders. The specimens are cored from a FRC beam, with a length of $650 \mathrm{~mm}$, and a square cross-section of $150^{2}$ $\mathrm{mm}^{2}$. These beams are tested in a three-point bending test according to the European Standard EN 14651 [16]. In total, 5 beams were cast. From each beam, two cores are taken, which are then rectified. The cylinders have a depth and diameter of $300 \mathrm{~mm}$ and $100 \mathrm{~mm}$, respectively. At the cylinder's mid-height, a notch is introduced with a depth and width of $10 \mathrm{~mm}$. From the 10 cored specimens, 2 cores are used to measure shrinkage and 8 specimens are precracked to an initial crack width $w_{\text {init }}=0.2$ $\mathrm{mm}$. The precracked, notched cores are then placed in a creep frame. An overview of the experimental phase is given in Fig. 1 .

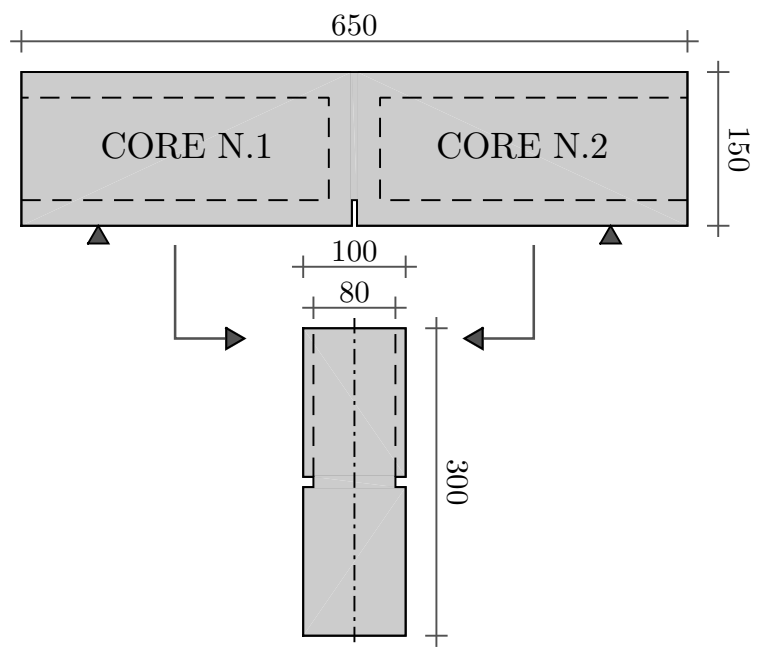

Figure 1: overview of cores N.1 and N.2 taken from beam $N$. All dimensions in $\mathrm{mm}$

\subsection{Material properties}

The concrete composition is taken from previous research on steel FRC [15] and is shown in Table 1 .

\begin{tabular}{ll}
\hline CEM I 42.5R HES & $350 \mathrm{~kg} / \mathrm{m}^{3}$ \\
sand (0/4) & $835 \mathrm{~kg} / \mathrm{m}^{3}$ \\
gravel (4/14) & $1099 \mathrm{~kg} / \mathrm{m}^{3}$ \\
water & $175 \mathrm{~kg} / \mathrm{m}^{3}$ \\
superplastizer & $1 \mathrm{~kg} / \mathrm{m}^{3}$ \\
fibers & $9 \mathrm{~kg} / \mathrm{m}^{3}$ \\
\hline
\end{tabular}

Table 1: concrete composition

In the composition above, the fiber volume fraction is equal to $1 \mathrm{Vol} . \%$. The properties of the fibers are shown in Table 2 .

\begin{tabular}{ll}
\hline material & polypropylene \\
length & $45 \mathrm{~mm}$ \\
strength $f_{t}^{\dagger}$ & $404.7 \mathrm{MPa}(1.8 \%)$ \\
Young's modulus $^{\dagger}$ & $4500 \mathrm{MPa}(1.5 \%)$ \\
\hline
\end{tabular}

Table 2: properties of the fiber ${ }^{\dagger}$ calculated according to the revision proposal of EN 14889-2 (shown in parentheses is the coefficient of variation)

\subsection{Three point bending setup}

In order to characterize the FRC, a threepoint bending test on 5 notched beams is performed according to the European Standard EN 14651 [16]. The beams are tested after 28 days. 
In this test, a notched square FRC beam with a span of $500 \mathrm{~mm}$ is tested in a displacementcontrolled regime. During the test, the force and crack mouth opening displacement (CMOD) are continuously measured at a rate of $5 \mathrm{~Hz}$. The setup is shown in Fig. 2
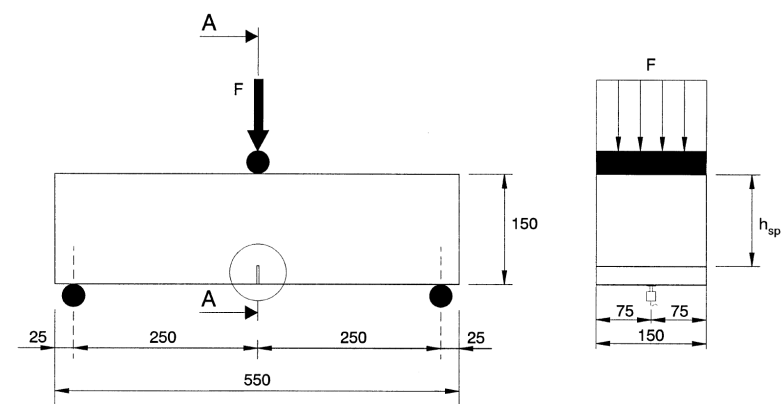

Figure 2: three point bending setup (taken from EN 14651)

\subsection{Precracking setup}

After rectifying the cores, the cylindrical specimens are notched at mid-height with a 10 $\mathrm{mm}$ deep notch. Before the precracking procedure can start, the specimens are glued between two steel plates, which are connected through 3 steel loading bars. These loading bars are outfitted with tying nuts and 3 strain gauges each. Furthermore, 3 linear variable differential transformers (LVDT) are glued over the notch at an $120^{\circ}$ angle to each other. These LVDTs can measure deformations up to $5 \mathrm{~mm}$. The setup is shown in Fig. 3 .

The precracking is done is a climate controlled room with constant temperature and relative humidity of $20{ }^{\circ} \mathrm{C}$ and $60 \%$, respectively. In order to precrack the specimen, three technicians manually tie the nuts (Fig. 3A) on the loading bars (Fig. 3C) to force the upper steel plate up, thereby applying a tensile load. The total tensile load is equal to the sum of the load in the loading bars. Care is taken to ensure that the measured deformation from the 3 LVDTs remains equal. As such, the precracking procedure is a displacement controlled test. The tension in each loading bar, as well as the deformation of every LVDT is continuously measured at a rate of $5 \mathrm{~Hz}$. During the test, the load is monotonously increased until cracking. After matrix cracking, the force in the loading bars was controlled such that uniform crack growth was imposed, i.e. care was taken to ensure that $w=w_{1}=w_{2}=w_{3}$. This was done until an average crack width $w_{\text {init }}=0.2 \mathrm{~mm}$ was obtained. Once $w_{\text {init }}$ was reached, the load was removed from the sample and the residual crack width $w_{\text {res }}$ was recorded.

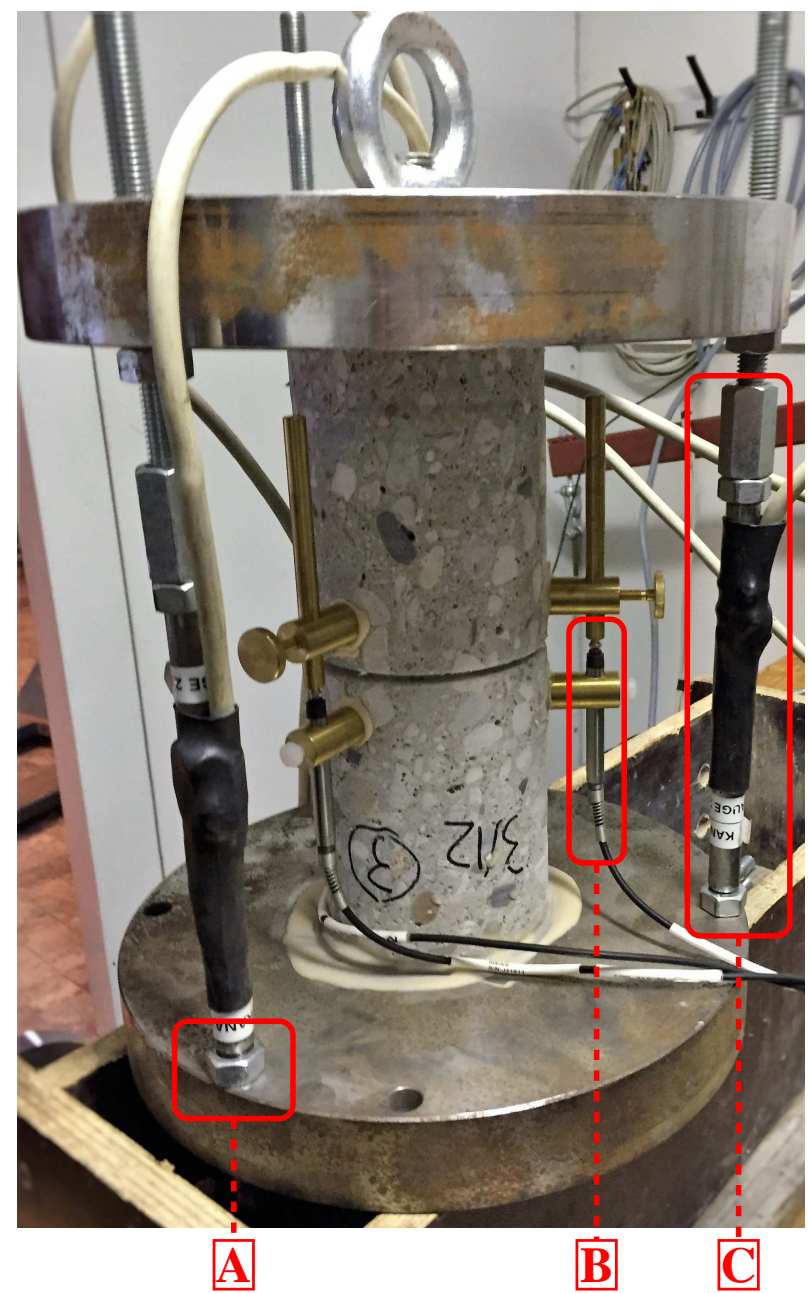

Figure 3: precracking setup with (A) a tying nut (B) an LVDT and (C) a loading bar

\subsection{Creep setup}

After precracking, the loading bars were replaced with ordinary threaded steel bars. These bars are used as a safety mechanism should the specimen fail during the creep test. The specimen is then placed in the creep frame. The creep frame consists of welded steel profiles and allows one specimen to be loaded by a con- 
stant load. The load is applied through a 6:1 cantilever system. Steel rings are used to minimize bending moment transfers to the specimen. The load is expressed as a percentage of $f_{r, w_{\text {init }}}$, the residual strength at $w=w_{\text {init }}$. In this paper, results are reported for specimens loaded at $30 \%$ and $45 \%$ of $f_{r, w_{i n i t}}$. The creep frame and a photo during the creep test is shown in Fig. 4 and Fig. 5, respectively.

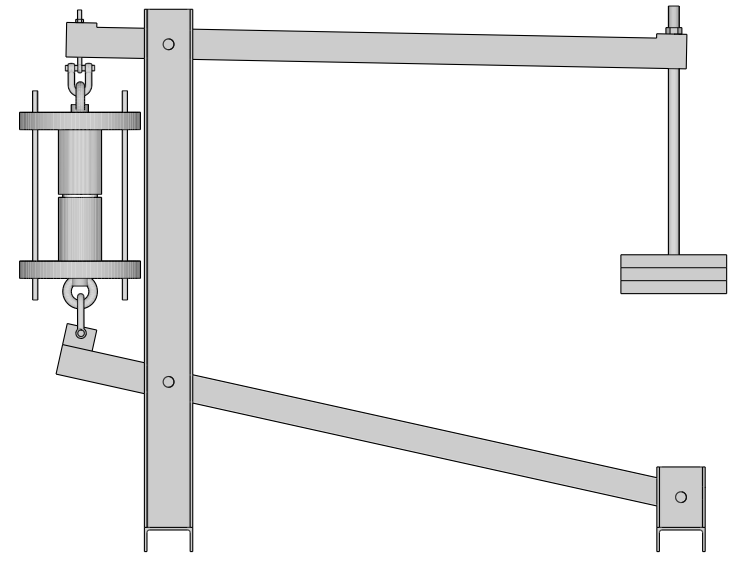

Figure 4: creep frame

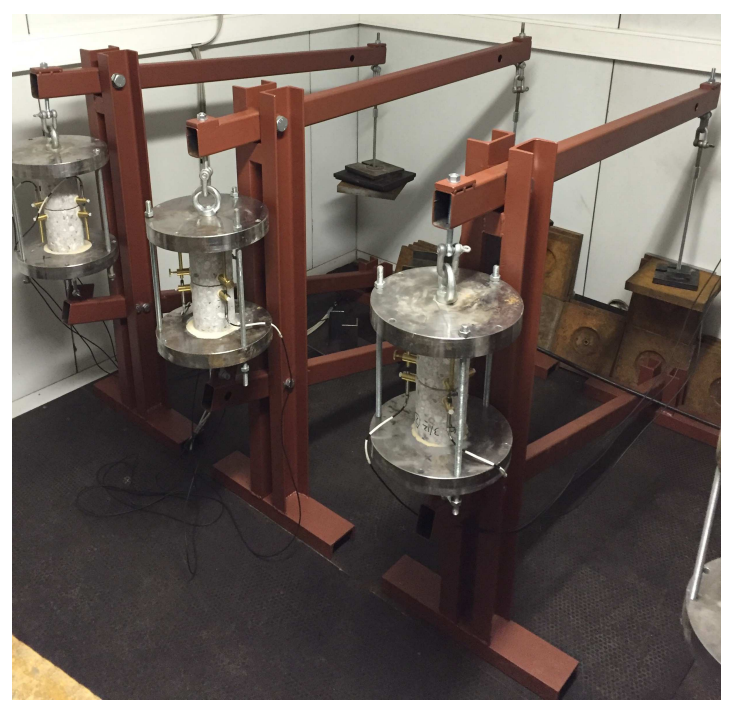

Figure 5: creep frames with specimens during creep test

During the test, the deformation from each LVDT is measured at a rate of $1 \mathrm{~Hz}$ during the first 24 hours of creep loading, and subsequently lowered to $0.1 \mathrm{~Hz}$. The cylinders are tested after 62 days in the same environmental conditions as during precracking.

\subsection{Shrinkage setup}

Two unprecracked, notched cores are used to measure the unconstrained drying shrinkage deformation. These shrinkage cores are exposed to the same environment as the creep specimens. The deformation is not continuously measured, but rather with the use of DEMEC points. Both shrinkage cores are fitted with 3 sets of DEMEC points at an $120^{\circ}$ degree angle to each other. At regular time intervals, the total deformation between the points of each pair is measured. A close-up of a pair of DEMEC points is shown in Fig. 6 .

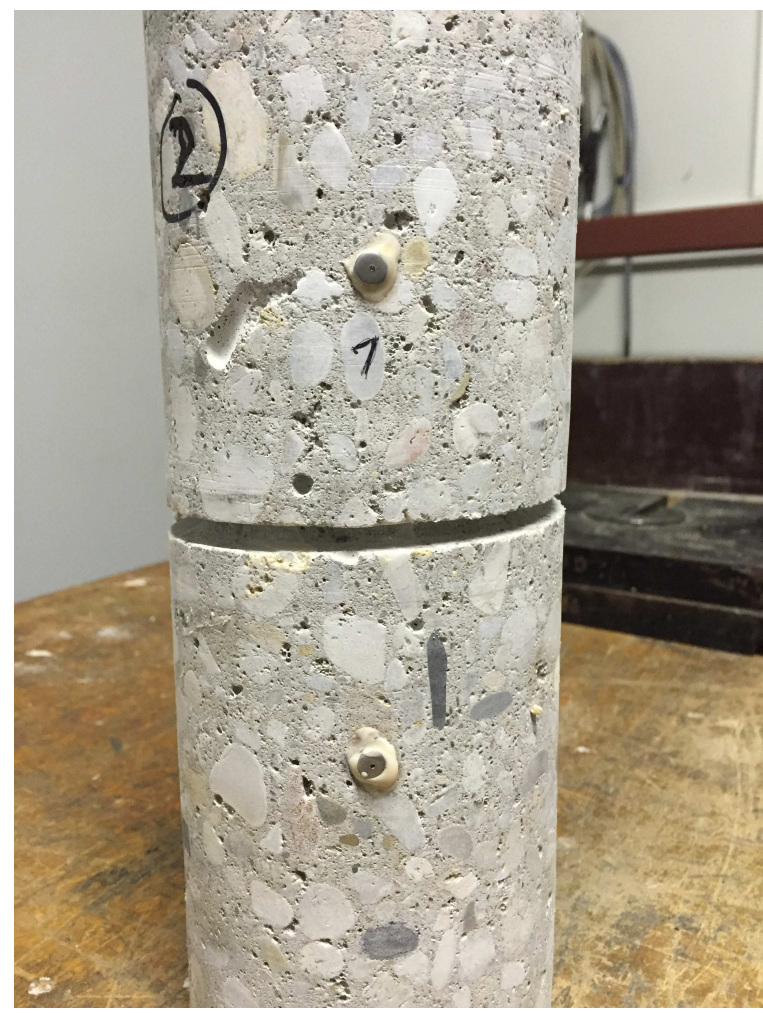

Figure 6: close-up of a pair of DEMEC points

\section{RESULTS}

\subsection{Material characterization}

The FRC compressive strength $f_{c}$ was determined by testing 3 cubes after 28 days according to EN 12390-3. From these tests, it was determined that $f_{c}=43.6 \mathrm{MPa}$ on average. The characterization for FRC is determined according to EN 14651, where the applied force and the CMOD is continuously measured. From this test, both the limit of proportionality 
$f_{L}$ (LOP) and the post-cracking tensile strength $f_{R j}$ are calculated. The LOP is the maximum observed strength for CMOD $\leq 0.05 \mathrm{~mm}$, while the post-cracking strength values are determined at four different CMODs, i.e. $\mathrm{CMOD}_{j}$ $=0.5 \mathrm{~mm}, 1.5 \mathrm{~mm}, 2.5 \mathrm{~mm}$ and $3.5 \mathrm{~mm}$, for $j=1,2,3,4$, respectively. The results are shown in Fig. 7

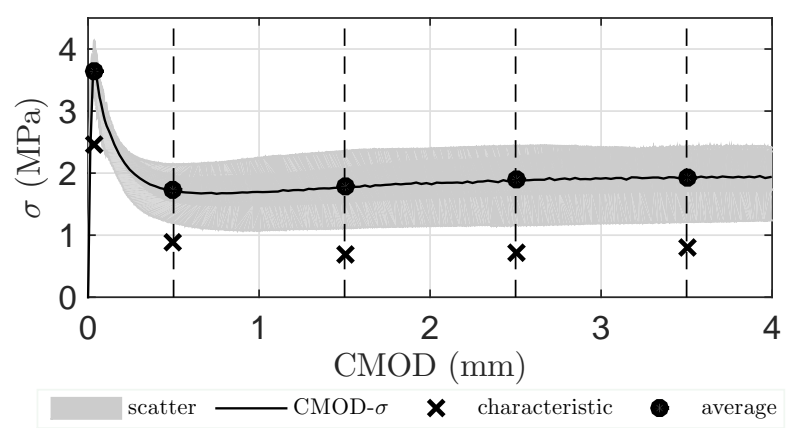

Figure 7: results of the characterization test on the beams

From the average values $\overline{f_{L}}$ and $\overline{f_{R j}}$ the characteristic values $f_{L k}$ and $f_{R j k}$ can be determined according to equation (1).

$$
f_{k}=\bar{f}-k_{n} \cdot s_{f}
$$

In Eq. (1), $f_{k}$ is the characteristic value, $\bar{f}$ the mean, and $s_{f}$ the standard deviation. The value $k_{n}$ depends on whether the coefficient of variation $V_{X}$ is known and on the number of available test samples $n$. For the $5 \%$ characteristic value, its value can be determined from table 3][17].

\begin{tabular}{lllll}
\hline$n$ & 4 & 5 & 6 & $\infty$ \\
\hline$V_{X}$ known & 1.83 & 1.80 & 1.77 & 1.64 \\
$V_{X}$ unknown & 2.63 & 2.33 & 2.18 & 1.64 \\
\hline
\end{tabular}

Table 3: values of $k_{n}$ for the $5 \%$ characteristic value [17]

For $n=5$ beams and $V_{X}$ not known, $k_{n}=2.33$. The results for all beams are shown in table 4

\begin{tabular}{llllll}
\hline beam & $f_{L}$ & $f_{R 1}$ & $f_{R 2}$ & $f_{R 3}$ & $f_{R 4}$ \\
\hline 1 & 3.76 & 1.56 & 1.55 & 1.66 & 1.72 \\
2 & 3.43 & 1.21 & 1.11 & 1.16 & 1.21 \\
3 & 4.14 & 2.13 & 2.35 & 2.43 & 2.36 \\
4 & 3.96 & 1.95 & 2.08 & 2.27 & 2.41 \\
5 & 2.87 & 1.76 & 2.01 & 2.21 & 2.31 \\
\hline & & & & & \\
$\bar{f}$ & 3.63 & 1.72 & 1.82 & 1.95 & 2.00 \\
$s_{f}$ & 0.50 & 0.36 & 0.49 & 0.53 & 0.52 \\
$f_{k}$ & 2.46 & 0.88 & 0.68 & 0.72 & 0.79 \\
\hline
\end{tabular}

Table 4: results for the beam tests with average and characteristic values, all values in $\mathrm{MPa}$

According to the Model Code 2010, FRC can be used to partially or entirely replace traditional reinforcement if $f_{R 1 k} / f_{L k}>0.4$ and $f_{R 3 k} / f_{R 1 k}>0.5$. For this concrete, $f_{R 1 k} / f_{L k}=$ 0.36 and $f_{R 3 k} / f_{R 1 k}=0.82$ such that strictly speaking, this material cannot be used to replace rebars. However, it should be noted that the Model Code is largely based on results on steel FRC, rather than PFRC. In the latter case, owing to polypropylene's lower-than-concrete Young's modulus, a significant drop in postcracking strength is to be expected at similar volume fractions as steel FRC. Furthermore, the first requirement is only barely not met.

\subsection{Precracking}

Before precracking, the three loading bars (Fig. 3C) were calibrated. For all bars, a nearperfect linear fit was found between the applied force and the measured strain. In Fig. 8 , the average measured strain is shown as a function of the applied force for all loading bars.

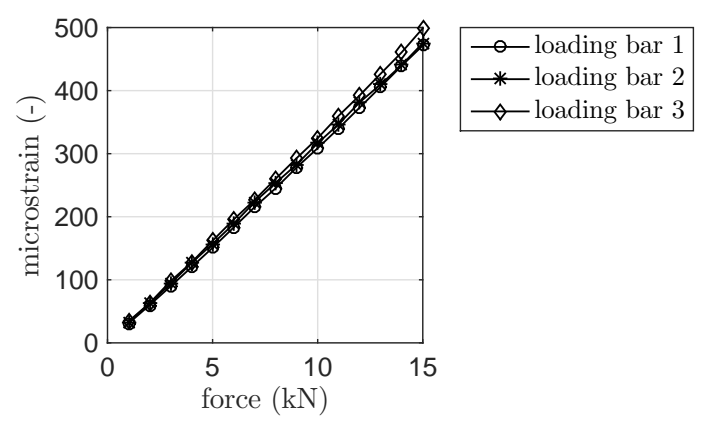

Figure 8: calibration results for all loading bars 
From the 8 specimens that were precracked, 6 cores cracked in the notched section. However, for two cores, the glue at the specimen's end failed and these two specimens (4.2 and 5.2) were discarded. The precracking results of the 6 specimens are shown in Fig. 9. These figures show the total measured force $F=$ $F_{\text {bar } 1}+F_{\text {bar } 2}+F_{\text {bar } 3}$ as a function of the average crack width $w=\left(w_{1}+w_{2}+w_{3}\right) / 3$. Note the equal axes scale for all results to highlight the differences between samples.
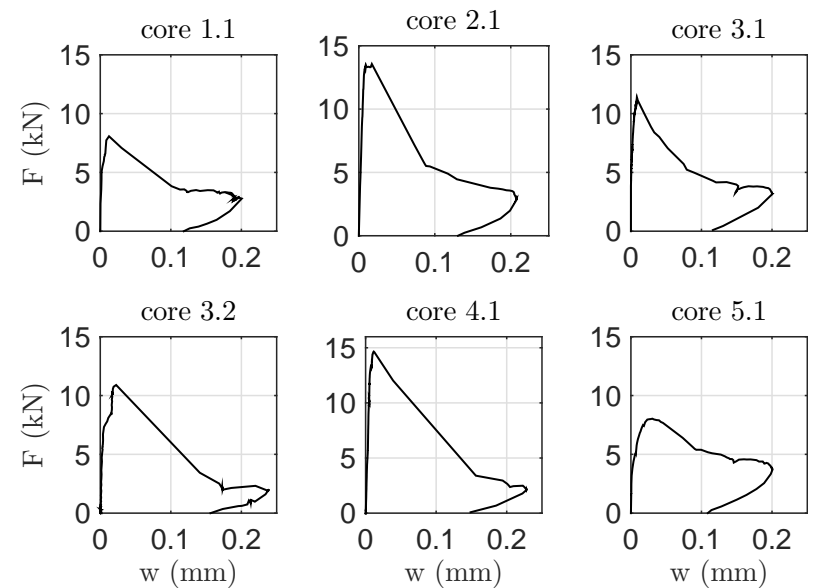

Figure 9: precracking results

For all specimens, the maximum measured force $F_{\max }$ during precracking was recorded, as well as the residual force $F_{w_{i n i t}}$ at $w=0.2 \mathrm{~mm}$. After load removal, the irreversible crack width $w_{i r r}$ is recorded as well. The results are shown in table 5. It can be noted that for two cores (3.2 and 4.1), the energy release at matrix cracking caused a near-instantaneous crack width greater than $w_{\text {precrack }}>w_{\text {init }}=0.2 \mathrm{~mm}$.

\begin{tabular}{lllll}
\hline core & $\begin{array}{l}F_{\max } \\
(\mathrm{kN})\end{array}$ & $\begin{array}{l}F_{w_{\text {init }}} \\
(\mathrm{kN})\end{array}$ & $\begin{array}{l}w_{\text {precrack }} \\
(\mathrm{mm})\end{array}$ & $\begin{array}{l}w_{\text {irr }} \\
(\mathrm{mm})\end{array}$ \\
\hline 1.1 & 8.19 & 2.8 & 0.20 & 0.12 \\
2.1 & 13.9 & 3.5 & 0.20 & 0.13 \\
3.1 & 11.3 & 3.5 & 0.20 & 0.11 \\
3.2 & 10.9 & 2.5 & 0.24 & 0.15 \\
4.1 & 14.7 & 2.5 & 0.23 & 0.14 \\
5.1 & 8.29 & 4.0 & 0.20 & 0.11 \\
\hline
\end{tabular}

Table 5: precracking results
After precracking, the six cores are placed in a creep frame. Two creep loads $F_{\text {creep }}$ are considered: 3 specimens are loaded at $30 \%$ of $F_{w_{\text {init }}}$; the other 3 cores at $45 \%$ of $F_{w_{\text {init }}}$, see table 6 .

\begin{tabular}{ll}
\hline$F_{\text {creep }} / F_{w_{\text {init }}}$ & core \\
\hline $30 \%$ & $1.1,2.1$ and 4.1 \\
$45 \%$ & $3.1,3.2$ and 5.1 \\
\hline
\end{tabular}

Table 6: creep loads considered

\subsection{Creep test}

In Fig. 10, the results of the first month of creep loading are presented. An overnight power outage in the first week after loading caused a shutdown of the measuring equipment, indicated by the gap in creep data.
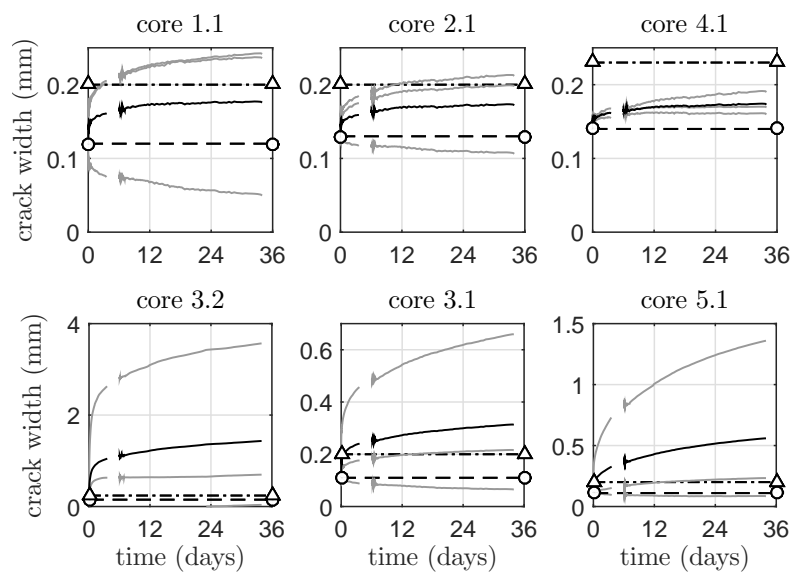

Figure 10: creep deformation after the first month of loading. Black and grey lines denote the average and individual LVDT readings, $-_{--\circ}$ is $w_{i r r}$ and $\Delta_{--} \Delta$ is $w_{\text {precrack }}$

\subsection{Shrinkage test}

The results of the unconstrained shrinkage test are shown in Fig. 11. The prediction by the Model Code 2010 is shown in a solid line. 


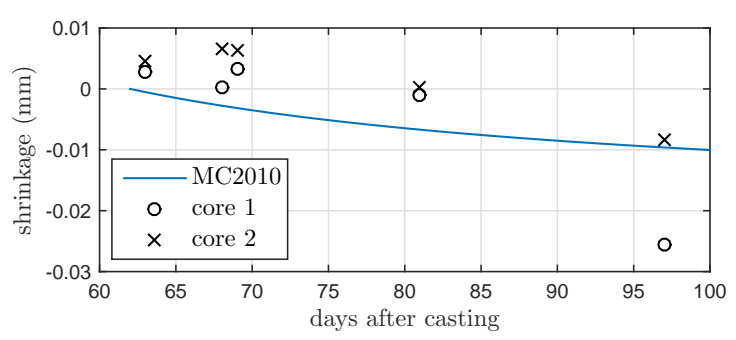

Figure 11: unconstrained shrinkage deformation

\section{DISCUSSION}

\subsection{Precracking}

After matrix cracking, the fibers take up the total load in the crack. Depending on the fiber volume fraction and fiber type, a strainhardening or strain-softening behavior can be observed. In the former case, the load further increases after cracking, while in the latter case, a drop-off in the force is observed. A strainhardening behavior is mostly associated with high volume fractions and/or very stiff fibers. For these specimens, a strain-softening behavior is observed. The force drop-off after cracking can be quite substantial and a very stiff test setup is needed to control the crack growth as the deformation energy of the matrix is released. In this case, a uniaxial strain-softening behavior was observed for all specimens.

Despite careful load application, the precracking procedure remained very difficult. In 4 out of 6 specimens, the formation of the crack, and the corresponding energy release caused a nearinstantaneous crack width greater than $0.1 \mathrm{~mm}$. In order to achieve a uniform crack growth after cracking, the forces in the loading bars may vary because of the random fiber distribution in the cracked section. Due to this randomness, significant differences are observed between cores as a higher fiber amount in the cracked section will also lead to higher postcracking strengths.

\subsection{Creep and shrinkage}

From Fig. 11, it is clear that the theoretical prediction by the Model Code 2010 is not accurate. However, it should be noted that the design rules for shrinkage in MC2010 are based on plain concrete, rather than FRC. In the literature, research has suggested that the inclusion of steel fibers reduces the free shrinkage with respect to plain concrete [2,18]. Furthermore, the presence of a notch increases the surface area exposed to drying, leading to an increase in shrinkage deformation. This cannot be taken into account with the simplified design rules in MC2010.

Despite differences between the experimental values and the theoretical prediction, it is clear that the shrinkage deformations are at least an order of magnitude smaller than the creep deformations.

The creep behavior of the specimens is largely determined by the applied creep load, as there is a noticeable difference between the cores loaded at $30 \%$ (cores $1.1,2.1,4.1$ ) and at $45 \%$ (cores 3.1, 3.2, 5.1). In the former case, the average crack width remains smaller than the precrack width $w_{\text {precrack }}$, while in the latter case, the average crack width exceeds $w_{\text {precrack }}$ within hours. For these higher loaded samples, the average crack width is an order of magnitude greater than allowed by MC2010 (0.2 $\mathrm{mm}$ or $0.3 \mathrm{~mm}$, depending on the application). These excessive crack width not only lead to a loss in durability, but possible also a loss of structural integrity. Furthermore, 5 cores exhibit a rotation during creep loading as well, indicated by the negative change of crack width measured by one LVDT. Only one core creeps uniformly, i.e. core 4.1. When comparing the average crack width of equally loaded cores, the importance of a uniform crack growth is underlined. Cores 1.1 and 2.1 exhibit a rotation during creep, core 4.1 does not. The average crack width of the latter is smaller than that of core 1.1 and 2.1. This highlights the need for a proper fiber distribution. However, care should be taken due to the small number of specimens and further research is needed.

\section{CONCLUSIONS}

The results of a uniaxial creep test after 1 month on polymeric FRC are presented. Spec- 
imens were cored from a beam, that has been used to characterize the FRC according to the European Standard EN 14651. The cored specimens were precracked to $w_{\text {init }}=0.2 \mathrm{~mm}$, after which they were subjected to a sustained axial tensile load. Two different stress levels were considered, i.e. $30 \%$ and $45 \%$ of the residual strength at $w=w_{\text {init }}$.

The results have shown that the stress levels play a major role in the creep behavior of the specimens. Samples loaded at $30 \%$ deformed considerably less and the average crack width remained below the precrack width. However, the average crack width of the higher loaded cores creeps to much higher values. Furthermore, the random fiber distribution in the crack can cause a rotation of the specimen during creep loading. It appears that this rotation can increase the average measured crack width. Simultaneously with the creep specimens, the shrinkage deformation of unrestrained cores is measured as well. The results show that while MC10 fails to accurately predict the shrinkage of FRC, the shrinkage is an order of magnitude smaller than the creep deformations. These experimental results highlight the need to take long-term behavior of FRC into account.

\section{ACKNOWLEDGMENTS}

The author gratefully acknowledges the financial support of the Agency for Innovation by Science and Technology in Flanders (IWT).

\section{REFERENCES}

[1] Balaguru, P., and Shah, S.P. 1992. FiberReinforced Cement Composites, McgrawHill, Texas USA.

[2] Bentur, A. and Mindess, S. 1990. Fibre Reinforced Cementitious Composites, Elsevier Science Publishers LTD. 449, England.

[3] di Prisco, M., Plizzari, G. and Vandewalle, L. 2009. Fibre reinforced concrete: new design perspectives. Materials and Structures, 42(9): p. 1261-1281.
[4] ACI Committee 544, Ed. Daniel, J.I. 2002. State-of-the-Art Report on Fiber Reinforced Concrete, American Concrete Institute.

[5] Ed. di Prisco, M, Felicetti, R. and Plizzari, G. 2004. Fibre-Reinforced Concrete. RILEM Proceedings of the 6th RILEM Symposium (BEFIB 2004), PRO39, BEFIB 2004, RILEM Publications S.A.R.L, Bagneux, France.

[6] Ed. Gettu, R., 2008. Fibre Reinforced Concrete: design and applications. BEFIB 2008, Rilem Publication S.A.R.L, Bagneux, France.

[7] Grzybowski, M. and Shah, S.P. 1990. Shrinkage Cracking of Fiber Reinforced Concrete. ACI Materials Journal, 87(2): p. $138-148$

[8] Pasini, F., et al. 2004. Experimental study of the properties of flowable fiber reinforced concretes, in 6th International RILEM Symposium on Fibre Reinforced Concretes, Ed. di Prisco, M., Felicetti, R., and Plizzari, G., p. 279 - 288.

[9] Barros, J., et al. 2005. Post-cracking behaviour of steel fibre reinforced concrete. Materials and Structures, 38(1): p. 47-56.

[10] di Prisco, M., Ferrara, L. and Lamperti, M. 2013. Double edge wedge splitting (DEWS): an indirect tension test to identify post-cracking behaviour of fibre reinforced cementitious composites. Materials and Structures, 46(11): p. 1893-1918.

[11] Buratti, N., Mazzotti, C. and Savoia, M. 2011. Post-cracking behaviour of steel and macro-synthetic fibre-reinforced concretes. Construction and Building Materials, 25(5): p. 2713-2722.

[12] fédération internationale du béton (fib), 2010. Model Code 2010 First complete draft. 
[13] Kurtz, S. and Balaguru, P. 2000. Postcrack creep of polymeric fiber-reinforced concrete in flexure. Cement and Concrete Research, 30(2): p. 183-190.

[14] MacKay, J. and Trottier, J. 2004. Postcrack creep behavior of steel and synthetic FRC under flexural loading. Shotcrete: More Engineering Developments, Taylor \& Francis. p. 183-192.

[15] Zhao, G., di Prisco M., Vandewalle L. 2014. Experimental investigation on uniaxial tensile creep behavior of cracked steel fiber reinforced concrete. Materials and Structures, 48(10): p. 3173-3185.
[16] European Committee for Standardization, 2005. EN 14651 Test method for metallic fibered concrete - Measuring the flexural tensile strength (limit of proportionality (LOP), residual).

[17] European Committee for Standardization, 2002. EN1990: Basis of structural design.

[18] Malmberg, B. and Skarendahl, A. 1978. Method of stuyding the cracking of fibre concrete under restrained shrinkage. Testing and test methods of Fibre Cement Composites. UK: The Construction Press. 